\title{
Using a top predator as a sentinel for environmental contamination with pathogenic bacteria: the Iberian wolf and leptospires
}

\author{
Javier Millán+, Emilio J García², Álvaro Oleaga ${ }^{3,4}$, José Vicente López-Bao ${ }^{5,6}$, Luis Llaneza ${ }^{2,7}$, \\ Vicente Palacios², Mónica G Candela ${ }^{8}$, Aitor Cevidanes ${ }^{9}$, Alejandro Rodríguez ${ }^{10}$, Luis León-Vizcaíno ${ }^{8}$
}

\begin{abstract}
${ }^{1}$ Facultad de Ecología y Recursos Naturales, Universidad Andres Bello, Santiago, Chile ${ }^{2}$ Asesores en Recursos Naturales SL, Lugo, Spain ${ }^{3}$ Sociedad de Servicios del Principado de Asturias SA, Asturias, Spain ${ }^{4}$ Instituto de Investigación en Recursos Cinegéticos, Consejo Superior de Investigaciones Científicas, Universidad de Castilla-La Mancha, Junta de Comunidades de Castilla-La Mancha, Ciudad Real, Spain ${ }^{5}$ Unidad Mixta de Investigación en Biodiversidad, Universidad de Oviedo-Consejo Superior de Investigaciones Científicas-Principado de Asturias, Mieres, Spain ${ }^{6}$ Grimsö Wildlife Research Station, Swedish University of Agricultural Sciences, Riddarhyttan, Sweden ${ }^{7}$ Departamento de Bioloxía Celular e Ecoloxía, Facultade de Bioloxía, Universidad de Santiago de Compostela, Santiago de Compostela, Spain ${ }^{8}$ Área de Enfermedades Infecciosas, Departamento de Sanidad Animal, Facultad de Veterinaria, Universidad de Murcia, Murcia, Spain ${ }^{9}$ Independent Consultant, Donostia-San Sebastián, Gipuzkoa, Spain ${ }^{10}$ Departamento de la Biología de la Conservación, Estación Biológica de Doñana, Consejo Superior de Investigaciones Científicas, Sevilla, Spain
\end{abstract}

The Iberian wolf (Canis lupus) is the top predator in the Iberian environments in which it lives, feeding on a wide range of species, thus encountering a wide range of disease agents. Therefore, the wolf can serve as sentinel of environmental contamination with pathogens. We investigated the exposure of free-living wolves to 14 serovars of Leptospira interrogans sensu lato. Kidney samples from 49 wolves collected from 2010-2013 in northwestern Spain were analysed by culture, direct immunofluorescence and polymerase chain reaction. Tissue fluids were analysed for antibodies by a microscopic agglutination test. Ten wolves (observed prevalence: 20\%, 95\% confidence interval $=11-33 \%)$ showed evidence of contact with leptospires, eight through direct detection and nine through serology (7 wolves were positive according to both techniques). Titres below the cut-off level were also detected in seven cases. Serovars confirmed were Canicola $(n=4)$, Icterohaemorrhagiae $(n=3)$ and Sejroë, Ballum and Grippotyphosa $(n$ $=1$ each), indicating that wolves were infected with serovars for which dogs, rodents and ungulates, are the natural hosts and supporting the utility of the wolf and other large predators as environmental sentinels for pathogens.

Key words: Carnivora - Leptospira borgpetersenii - spirochete

Leptospirosis is a disease of public health and veterinary importance caused by pathogenic spirochetes of the genus Leptospira. The disease is distributed worldwide and is known to affect humans, domestic animals and wildlife. Leptospires exploit some mammal species as reservoir hosts by establishing chronic infections in the renal tubules of the kidneys ("carrier phase") that can persist for months or longer. From this niche, bacteria are shed in urine, contaminating the environment. Susceptible hosts thus acquire infection indirectly from infected animals by coming into contact with environmental bacteria (Birtles 2012), though direct contact can also take place (Levett 2001). The Genus Leptospira includes more than 17 species and is subdivided into a large number of antigenically distinct serovars, many of which have been associated with particular mammalian reservoir hosts and therefore have ecological relevance (Birtles 2012).

A sentinel species is one used to collect information about disease. For example, scavenging or carnivorous species screen a large number of species at a lower trophic level. Measuring evidence of disease in the car-

doi: $10.1590 / 0074-0276140258$

Financial support: Ministerio de Ciencia e Innovación (CGL2010-17931)

+ Corresponding author: syngamustrachea@hotmail.com

Received 18 July 2014

Accepted 19 November 2014 nivore/scavenger provides an index to the relative frequency of occurrence of disease (Wobeser 2007). Most members of the order Carnivora are wide-ranging, generalist species that can be useful as sentinels to determine the presence and relative importance of different serovars of Leptospira in the environment (Millán et al. 2009). The wolf (Canis lupus) is one of the three large predators inhabiting the Iberian Peninsula, showing a remarkable range in the region (ca. $140,000 \mathrm{~km}^{2}, 25 \%$ of Iberia) (Blanco \& Cortés 2012) and a high level of tolerance to human activities (Llaneza et al. 2012). Iberian wolves feed on a wide range of preys, from small mammals to large ungulates, both wild and domestic, poultry and carrion (Cuesta et al. 1991). Taking into account the ecological role of wolves in ecosystems, its generalist nature and its range, Iberian wolves may serve as good sentinels for environmental monitoring of infectious agents or pollutants in Iberia. The aim of this study was to explore the potential role of wolves as sentinels of environmental contamination with pathogenic leptospires.

\section{MATERIALS AND METHODS}

We collected samples of 49 dead wolves (causes of death: legal hunting, road kill and illegal killing) from 2010-2013 in two regions of northwestern Spain: Asturias $\left(43^{\circ} 28^{\prime} \mathrm{N} 5^{\circ} 27^{\prime} \mathrm{O}\right)$ and Galicia $\left(43^{\circ} 17^{\prime} \mathrm{N} 7^{\circ} 41^{\prime} \mathrm{O}\right)$. Carcasses were collected as part of a long-term collection protocol of wolf samples approved by the Regional 
Governments of Galicia and Asturias. This sample size represents about $2.5 \%$ of the wolves inhabiting the Iberian Peninsula (estimated in 2,000 individuals) (Blanco $\&$ Cortés 2012). Kidney samples were obtained and kept frozen until analyses. Once in the laboratory, samples were subjected to three types of analyses. Direct immunofluorescence (IF) was carried out using Rabbit IgG against a pool of the studied serovars of Leptospira (made in-house) and goat anti-rabbit IgG-fluorescein isothiocyanate conjugate (Nordic Immunological Laboratories, Netherlands) following the procedure of LeónVizcaíno et al. (1987). The serovars investigated were Australis, Autumnalis, Ballum, Bataviae, Bratislava, Canicola, Grippotyphosa, Hardjo, Hebdomadis, Icterohaemorrhagiae, Pomona, Saxkoebing, Sejroë and Tarassovi. The strains used can be found in Millán et al. (2009). Culture was carried out using a standard Ellinghausen-McCullough-Johnson-Harris (EMJH) (Difco Laboratories, Madrid, Spain) liquid medium following the procedures of Baranton and Postic (1989). Kidney samples were homogenised in a 1:10 dilution with EMJH medium (Difco). Homogenate samples were subjected to DNA extraction, performed as described by Rojas et al. (2010) using a commercial kit (QIAamp DNA Mini Kit; Qiagen Iberia, Spain). Extracted DNA was quantified using spectrophotometry at $260 \mathrm{~nm}$. Polymerase chain reaction (PCR) was performed as described by Moreno and Agudelo-Flórez (2010) using primers LipL32/270F (5'-CGCTGAAATGGGAGTTCGTATGATT-3') and LipL32/662R (5'-CCAACAGATGCAACGAAAGATCCTTT-3) as reported by Levett et al. (2005). No-template controls were included in PCRs. PCR was performed in a Biometra T Personal (Biometra, Germany) thermocycler and PCR products were visualised through electrophoresis on a $1.5 \%$ agarose gel stained with ethidium bromide and viewed under ultraviolet light. Positive DNA extractions were amplified by PCR in order to differentiate Leptospira serovars detecting the oligonucleotide i-Repl as a target of the amplification (Barocchi et al. 2001, Rojas et al. 2010). PCR was performed as described by Rojas et al. (2010) using the primers Rep1 (5'- AGCGGGTATGACTCCGC-3') and iRep1 (5'GCGGACTCATACCCGCT-3') (Barocchi et al. 2001). To detect antibodies against such serovars, kidney tissue exudates were analysed by the indirect microscopic agglutination test following procedures outlined in Faine (1982), which is the standard method to detect antibodies against Leptospira serovars. We considered 1:100 the cut-off point for positive sera. Differences in prevalence between seasons, regions and age (pups: younger than 1 year; subadult: between 1-2 years; adult: older than 2 years) and sex groups were tested with the $\chi^{2}$ test or Fisher's exact test using PASW Statistics 17.0.

\section{RESULTS}

Ten wolves (observed prevalence: $20.1 \%$, $95 \%$ confidence interval $=11-33 \%$ ) showed evidence of contact with leptospires (Table). Eight wolves were actively infected as revealed by direct detection (16.3\%); of these, three were positive by PCR and IF and five only by PCR. All wolves were negative for culture. Nine wolves had antibodies

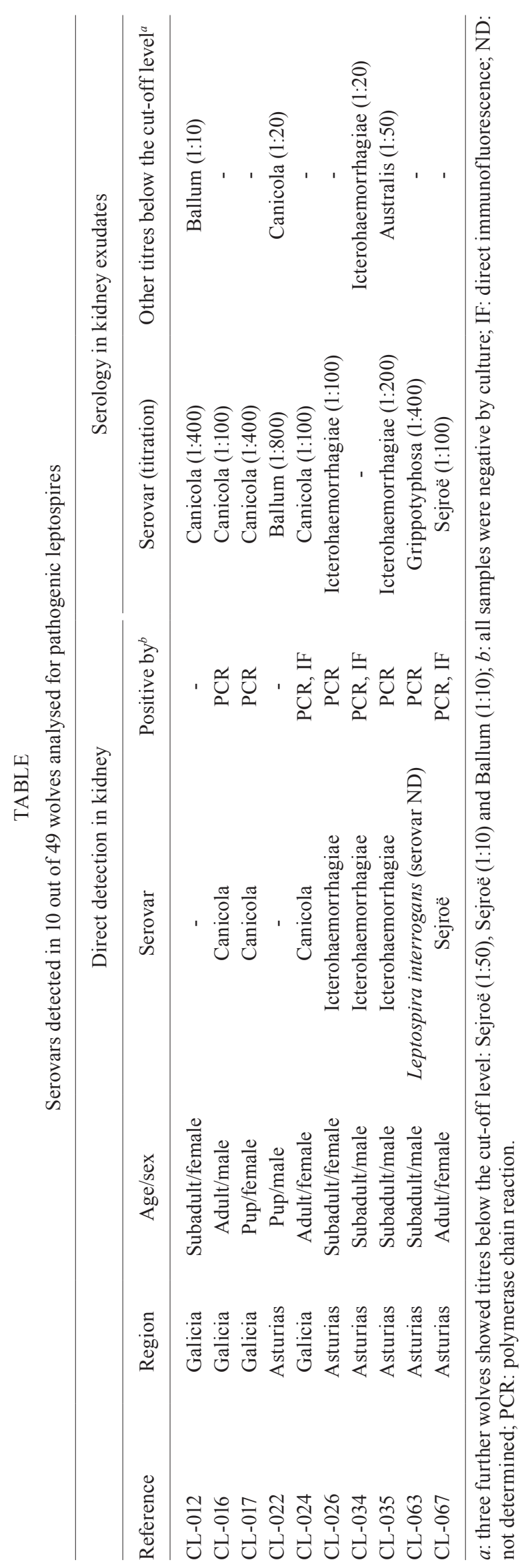


(18.3\%). Seven wolves were positive for both antibodies and leptospires. Overall, serovars detected were Canicola $(\mathrm{n}=4,40 \%$ of the positive cases), Icterohaemorrhagiae ( $\mathrm{n}$ $=3,30 \%)$ and Sejroë, Ballum and Grippotyphosa $(\mathrm{n}=1$, $10 \%$ each). Four of the seropositive wolves and three further wolves showed titres against other serovars, including serovar Australis, but below the cut-off level (Table). No differences were found in prevalence depending on the diverse factors studied (see Materials and Methods). Interestingly, a wolf pup had high antibody titres against serovar Ballum, but was apparently uninfected.

\section{DISCUSSION}

The prevalence detected in the present survey is higher than reported for wolf populations elsewhere. Very low seroprevalences were found in Alaska (Zarnke et al. 2004) and Scandinavia (Akerstedt et al. 2010). In Minnesota, about $10 \%$ of wolves were seropositive (Khan et al. 1991). Warmer winters in northwestern Spain, as compared to these northern locations and relatively wet summers, probably enhance the survival of spirochetes in the environment. However, the difference observed with previous studies might only be a result of the convenience sampling used in this study compared with samples obtained from live-trapped animals in all other studies quoted (Khan et al. 1991, Zarnke et al. 2004, Akerstedt et al. 2010).

Our study reveals, for the first time, active Leptospira infection in wolves. It is noteworthy that seroprevalence was only slightly higher than prevalence of active infections, whereas previous studies in wild carnivores using both techniques showed that this difference is usually marked (Millán et al. 2009, Moinet et al. 2010). The lack of such differences in the present study may result from a poor performance of the serological test due to the use of tissue exudates instead of serum. Alternatively, discrepancies may also indicate a short life of circulating antibodies in wolves or a low degree of seroreactivity. In fact, antibody titres were low $(1: 100)$ in four wolves that were concurrently infected. In addition, titres below the cut-off level were detected in other cases, suggesting the existence of chronic infections in wolves that could be acting as renal carriers (Table).

Our results confirm wolf exposure to leptospires of different origins. Dogs are considered the natural host for serovar Canicola (André-Fontaine 2006), though other species can be found infected by this serovar (García et al. 2013). Given the genetic proximity between wolves and dogs, it is not surprising that this was the most prevalent serovar detected in the present survey. However, this was not the case in the study by Khan et al. (1991) in Minnesota, where this serovar was only the fourth most frequently detected. These differences may reflect the fact that Iberian wolves live in a more anthropised environment (Llaneza et al. 2012) and that wolves occurring in human-dominated landscapes may be frequently exposed to canine pathogens.

The main reservoirs for the serovars Icterohaemorragiae, Sejroë and Ballum are rodents (Turk et al. 2003, André-Fontaine 2006). No information is available about leptospiral infections in rodents in the study areas. In a nearby region in western Spain, the most com- mon serovar found was Ballum (García et al. 2013). The abovementioned serovars were almost absent in wild ungulates in Asturias, as recently published (Espí et al. 2010). Therefore, wolves may come into contact with these serovars after consumption of rodents or perhaps lagomorphs, as suspected in other studies analysing wild carnivores in Southern Europe (Millán et al. 2009, Moinet et al. 2010). However, the proportion of these food items is very low or absent in the diets of wolves from the study areas (Llaneza et al. 1996, López-Bao et al. 2013). An alternative hypothesis may be that the wolves became infected after drinking from rodent-contaminated water sources or from consuming other preys or carrion of ungulates that can occasionally be infected by these serovars (Slavica et al. 2008, Espí et al. 2010).

Serovar Grippotyphosa, also detected in the present survey, was the most seroprevalent in wolves from Minnesota, representing one in four positive cases (Khan et al. 1991). Antibodies against this serovar were among the most frequently detected in the survey of wild ungulates in Asturias by Espí et al. (2010), especially in fallow deer (Dama dama) and wild boar (Sus scrofa). Antibodies against serovar Grippotyphosa were also relatively prevalent in cattle farms in Galicia and Asturias (Espí et al. 2000, Guitián et al. 2001). Thus, wolves probably come into contact with this serovar after consumption of wild or domestic ungulates or their products.

The disease significance of infection with leptospires for wolves is unknown. Lesions (chiefly chronic interstitial nephritis) associated with leptospiral infection have been recorded in other species of wild carnivores (Millán et al. 2009). In dogs, leptospires can cause hepatic and renal failure and, occasionally, death (Greene et al. 2012). It is generally assumed that serovars Icterohaemorrhagiae and Canicola are responsible for the acute forms of canine leptospirosis. However, typical acute leptospirosis can also be induced by strains belonging to other serogroups, including Grippotyphosa (André-Fontaine 2006).

In conclusion, our survey revealed infection and exposure in wolves with serovars maintained by different reservoirs such as dogs, rodents and ungulates, confirming the usefulness of the wolf and other large predators as an environmental sentinel for leptospires and probably other environmental pathogens.

\section{ACKNOWLEDGEMENTS}

To the rangers and technicians of the game preserves, Jaime Marcos Beltrán and Francisco Alonso Mier, for submitting carcasses, to the colleagues from SERIDA (Alberto Espí) and the Faculty of Veterinary USC (Luis Eusebio Fidalgo Álvarez and Ana María López Beceiro), for assistance in necropsy and laboratory work, and to the agreement between CSIC and Principado de Asturias.

\section{REFERENCES}

Akerstedt J, Lillehaug A, Larsen IL, Eide NE, Arnemo JM, Handeland K 2010. Serosurvey for canine distemper virus, canine adenovirus, Leptospira interrogans and Toxoplasma gondii in free-ranging canids in Scandinavia and Svalbard. $J$ Wildl Dis 46: 474-480.

André-Fontaine G 2006. Canine leptospirosis - do we have a problem? Vet Microbiol 117: 19-24. 
Baranton G, Postic D 1989. Méthodes de laboratoire: leptospiroseborreliose de Lyme, Institute Pasteur, Paris, 107 pp.

Barocchi MA, Ko AI, Ferrer SR, Faria MT, Reis MG, Riley LW 2001. Identification of new repetitive element in Leptospira interrogans serovar copenhageni and its application to PCR-based differentiation of Leptospira serogroups. J Clin Microbiol 39: 191-195.

Birtles R 2012. Leptospira infections. In D Gavier-Widén, JP Duff, A Meredith, Infectious diseases of wild mammals and birds in Europe, Wiley-Blackwell, Oxford, p. 402-408.

Blanco JC, Cortés Y 2012. Surveying wolves without snow: a critical review of the methods used in Spain. Hystrix 23: 35-48.

Cuesta L, Bárcena F, Palacios F, Reig S 1991. The trophic ecology of the Iberian wolf (Canis lupus signatus Cabrera, 1907) - a new analysis of stomachs data. Mammalia 55: 239-254.

Espí A, Prieto JM, Alzaga V 2010. Leptospiral antibodies in Iberian red deer (Cervus elaphus hispanicus), fallow deer (Dama dama) and European wild boar (Sus scrofa) in Asturias, northern Spain. Vet J 183: 226-227.

Espí A, Prieto JM, Fernandez M, Álvarez M 2000. Serological prevalence to six leptospiral serovars in cattle in Asturias (northern Spain). Epidemiol Infect 124: 599-602.

Faine S 1982. Guidelines for the control of leptospirosis, WHO, Geneva, 98 pp.

García A, Martínez R, García L, Benítez-Medina JM, Risco D, García WL, Rey J, Alonso JM, Kodjo A 2013. Prevalence of Shiga toxin-producing Escherichia coli and pathogenic Leptospira spp in rodents from outdoor farms in western Spain. Turk Vet Hayvanc Dergis 37: 750-753.

Greene CE, Sykes JE, Moore GE, Goldstein RE, Schultz RD 2012. Leptospirosis. In CE Green, Infectious diseases of the dog and cat, 4th ed., Saunders Elsevier, St Louis, p. 431-447.

Guitián FJ, García-Peña FJ, Oliveira J, Sanjuán ML, Yus E 2001. Serological study of the frequency of leptospiral infections among dairy cows in farms with suboptimal reproductive efficiency in Galicia, Spain. Vet Microbiol 80: 275-284.

Khan MA, Goyal SM, Diesch SL, Mech LD, Fritts SH 1991. Seroepidemiology of leptospirosis in Minnesota wolves. J Wildl Dis 27: 248-253.

León-Vizcaíno L, Hermoso M, Garrido G 1987. Incidence of abortions caused by leptospirosis in sheep and goats in Spain. Comp Immunol Microbiol Infect Dis 10: 149-153.

Levett P, Morey R, Galloway R, Turner D, Steigerwalt A, Mayer L 2005. Detection of pathogenic leptospires by real-time quantitative PCR. J Med Microbiol 54: 45-49.
Levett PN 2001. Leptospirosis. Clin Microbiol Rev 14: 296-326.

Llaneza L, Fernández A, Nores C 1996. Dieta del lobo en dos zonas de Asturias (España) que difieren en carga ganadera. Doñana, Acta Vertebrata 23: 201-213.

Llaneza L, López-Bao JV, Sazatornil V 2012. Insights into wolf presence in highly human-dominated landscapes: the relative role of food availability, human activity and landscape attributes. Divers Distrib 18: 459-469.

López-Bao JV, Sazatornil V, Llaneza L, Rodríguez A 2013. Indirect effects on heathland conservation and wolf persistence of contradictory policies that threaten traditional free-ranging horse husbandry. Conserv Lett 6: 448-455.

Millán J, Candela MG, López-Bao JV, Pereira M, Jiménez MA, LeónVizcaíno L 2009. Leptospirosis in wild and domestic carnivores in natural areas in Andalusia, Spain. Vector Borne Zoonotic Dis 9: 549-554.

Moinet M, Fournier-Chambrillon C, André-Fontaine G, Aulagnier $\mathrm{S}$, Mesplède A, Blanchard B, Descarsin V, Dumas P, Dumas Y, Coïc C, Couzi L, Fournier P 2010. Leptospirosis in free-ranging endangered European mink (Mustela lutreola) and other small carnivores (Mustelidae, Viverridae) from southwestern France. $J$ Wildl Dis 46: 1141-1151.

Moreno N, Agudelo-Flórez P 2010. Application of conventional and multiplex PCR assays for identification of isolates of Leptospira spp in Colombia. Rev Peru Med Exp Salud Publica 27: 548-556.

Rojas P, Monahan AM, Schuller S, Miller IS, Markey BK, Nally JE 2010. Detection and quantification of leptospires in urine of dogs: a maintenance host for the zoonotic disease leptospirosis. Eur $J$ Clin Microbiol Infect Dis 29: 1305-1309.

Slavica A, Cvetnic Z, Milas Z, Janicki Z, Turk N, Konjevic D, Severin $\mathrm{K}$, Tonèië J, Lipej Z 2008. Incidence of leptospiral antibodies in different game species over a 10-year period (1996-2005) in Croatia. Eur J Wildl Res 54: 305-311.

Turk N, Milas Z, Margaletic J, Staresina V, Slavica A, Riquelme-Sertour N, Bellenger E, Baranton G, Postic D 2003. Molecular characterization of Leptospira spp strains isolated from small rodents in Croatia. Epidemiol Infect 130: 159-166.

Wobeser GA 2007. Disease in wild animals: investigation and management, Springer, Berlin, 393 pp.

Zarnke RL, Hoef JMV, DeLong RA 2004. Serologic survey for selected disease agents in wolves (Canis lupus) from Alaska and the Yukon Territory, 1984-2000. J Wildl Dis 40: 632-638. 